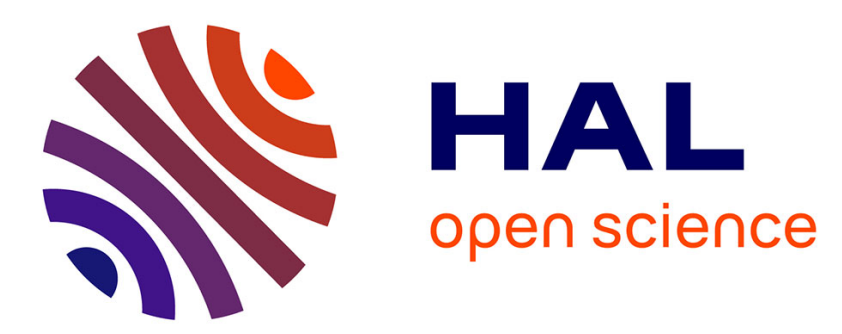

\title{
Zinc oxide-hydroxyapatite nanocomposite photocatalysts for the degradation of ciprofloxacin and ofloxacin antibiotics
}

C. El El Bekkali, H. Bouyarmane, M. El Karbane, S Masse, A. Saoiabi, T.

Coradin, A. Laghzizil

\section{To cite this version:}

C. El El Bekkali, H. Bouyarmane, M. El Karbane, S Masse, A. Saoiabi, et al.. Zinc oxidehydroxyapatite nanocomposite photocatalysts for the degradation of ciprofloxacin and ofloxacin antibiotics. Colloids and Surfaces A: Physicochemical and Engineering Aspects, 2018, 539, pp.364-370. 10.1016/j.colsurfa.2017.12.051 . hal-01685476

\section{HAL Id: hal-01685476 https: / hal.sorbonne-universite.fr/hal-01685476}

Submitted on 16 Jan 2018

HAL is a multi-disciplinary open access archive for the deposit and dissemination of scientific research documents, whether they are published or not. The documents may come from teaching and research institutions in France or abroad, or from public or private research centers.
L'archive ouverte pluridisciplinaire HAL, est destinée au dépôt et à la diffusion de documents scientifiques de niveau recherche, publiés ou non, émanant des établissements d'enseignement et de recherche français ou étrangers, des laboratoires publics ou privés. 


\section{Zinc oxide-hydroxyapatite nanocomposite photocatalysts for the degradation of ciprofloxacin and ofloxacin antibiotics}

C. El Bekkali, ${ }^{a}$ H. Bouyarmane, ${ }^{\text {a }}$ M. El Karbane, ${ }^{b}$ S. Masse, ${ }^{c}$ A. Saoiabi, ${ }^{a}$ T. Coradin,,${ }^{*}$ A. Laghzizil $^{\mathrm{a}, *}$

${ }^{a}$ Laboratoire de Chimie Appliquée des Matériaux, Université Mohammed V, Faculté des Sciences BP.1014 Rabat, Morocco

${ }^{b}$ Laboratoire National de Contrôle des Médicaments, Rabat, Morocco

${ }^{c}$ Sorbonne Universités, UPMC Univ Paris 06, CNRS, Collège de France, UMR 7574, Laboratoire de Chimie de la Matière Condensée de Paris, F-75005 Paris, France

*corresponding authors

thibaud.coradin@upmc.fr (T. Coradin); 1aghzizi@,fsr.ac.ma (A. Laghzizil) 


\begin{abstract}
Zinc oxide-hydroxyapatite nanocomposites were prepared from a natural phosphate ore via a solvent-free method and evaluated for the photodegradation of two antibiotics in solution. The in situ growth of $\mathrm{ZnO}$ followed by thermal treatment allowed for the formation of photocatalytic nanocrystals homogeneously dispersed in the apatite phase. Nanocomposites exhibited higher rates of sorption of ofloxacin and ciprofloxacin compared to the individual phases. At high $\mathrm{ZnO}$ loadings, photodegradation performances of the nanocomposites under UV irradiation were equivalent or greater than that of the photocatalytic particles alone, depending on the considered antibiotic. This dependency reflects distinct degradation pathways that were attributed to different affinities of the antibiotics for the nanocomposite particles. Because of its simplicity and versatility, the here-described approach appears very promising for the development of multifunctional platforms for water remediation.
\end{abstract}

Keywords: Photodegradation; Hydroxyapatite; Zinc Oxide; Nanocomposites; Antibiotics 


\section{Introduction}

Pharmaceutical pollutants represent major contaminants for the water resources whose sanitary and environmental impacts are now fully taken into account and estimated $[1,2]$. They form a wide class of molecules having variable physical and chemical properties, making them particularly complex to eliminate from wastewaters [3,4]. For instance, the majority of pharmaceuticals are relatively hydrophobic and therefore less effectively removed by simple sorption processes $[5,6]$. Moreover, due to their intrinsic biological activity, their partial or complete degradation prior to discharge is highly recommended [2]. With this purpose, ozonation and other advanced oxidation technologies have been described [7,8], among which photodegradation appears particularly promising [9]. This technology relies on the use of a photocatalytic material, in most cases a nanoscale semiconductor, able to generate highly oxidative species under light excitation [10]. While titanium dioxide remains the most popular photocatalyst used for pharmaceuticals photodegradation [11], zinc oxide has also shown interesting potentialities in this field [12,13].

The benefits of associating nanoscale photocatalysts with a complementary phase within composite structures have been demonstrated at several occasions [14]. In the case of $\mathrm{ZnO}$-based nanocomposites, it can allow for a pre-concentration of the organic molecules at the vicinity of the photocatalysts, favor the dispersion of the photoactive phase and therefore increase the available reactive surface, permit shaping and recovery of the photoactive material, enhance intrinsic photocatalytic properties and lead to the design of multifunctional materials exhibiting magnetic properties or being able to degrade organics and retain toxic metals [15-20].

Among sorbing phases that may be advantageously associated with $\mathrm{ZnO}$, hydroxyapatite $\left(\mathrm{Ca}_{10}\left(\mathrm{PO}_{4}\right)_{6}(\mathrm{OH})_{2}\right)$ appears particularly interesting due to its high capacity for metal ions retention and good sorption properties towards certain organic pollutants, including antibiotics [21-26]. The 
co-precipitation of hydroxyapatite-based nanocomposites with other inorganic phases, such as $\mathrm{ZrO}_{2}, \mathrm{Fe}_{3} \mathrm{O}_{4}$ or $\mathrm{TiO}_{2}$, for remediation purpose has already been described [27-29]. In particular, Ti-doped hydroxyapatites have shown very promising properties as photocatalysts [30-33]. Elaborating on these results, we have prepared here hydroxyapatite- $\mathrm{ZnO}$ nanocomposites and evaluated their photodegradation efficiency towards two antibiotics belonging to the fluoroquinone family, ciprofloxacin and ofloxacin. In addition to their widespread use, these pharmaceuticals were selected for their previously-reported good affinity for hydroxyapatite surfaces [26]. Other catalysts have been used for the photodegradation of ciprofloxacin such as $\mathrm{TiO}_{2}$-montmorillonite [34], iron [35] and $\mathrm{ZnWO}_{4}-\mathrm{CdS}$ [36]. In addition, the photocatalytic degradation of ofloxacin was studied on $\mathrm{Bi}_{2} \mathrm{O}_{3} / \mathrm{TiO}_{2}$ [37]. We show that a purely aqueous synthetic route combining natural phosphate ore and a zinc salt leads to nanosized powders where $\mathrm{ZnO}$ photocatalysts are homogeneously associated with the hydroxyapatite particles. We could evidence that the nanocomposites exhibit faster rates of antibiotics sorption compared to both individual phases and, for the highest zinc oxide loadings, similar or faster photodegradation rates

than pure $\mathrm{ZnO}$. Our data show that the two antibiotics, although being of similar chemical structure, undergo distinct degradation pathways, that are discussed in terms of surface affinity and diffusion issues.

\section{Experimental}

\subsection{Preparation and characterization of the HAp-ZnO nanocomposites (wZnHAp)}

The pure hydroxyapatite powder (HAp) was prepared by a dissolution/reprecipitation method from a natural phosphate ore coming from the Bengurir region (Morocco) as previously described [38]. The dissolution of the ore was carried out by introducing $30 \mathrm{~g}$ of the collected raw material in a 2 
$\mathrm{L}$ reactor containing $500 \mathrm{~mL}$ of deionized water acidified to $\mathrm{pH} 2$ by addition of $20 \mathrm{~mL}$ of concentrated $\mathrm{HNO}_{3}$ acid (65\%), under continuous stirring for 3 hours at room temperature. After filtration, the recovered solution containing calcium and phosphate ions was brought to $\mathrm{pH} 10$ by addition of a concentrated ammonia solution ( $25 \%)$. The resulting precipitate was aged for $24 \mathrm{~h}$, filtered and washed three times with deionized water with intermediate ultrasound irradiation steps to optimize grain dispersion. Finally, the powder was dried in an oven at $100{ }^{\circ} \mathrm{C}$ for $24 \mathrm{~h}$ and, when noted, heated to $500^{\circ} \mathrm{C}$ for $3 \mathrm{~h}$.

Among methods available for zinc oxide synthesis [39], the precipitation route through alkalinization of an acidic solution of zinc nitrate dihydrate $\mathrm{Zn}\left(\mathrm{NO}_{3}\right)_{2} \cdot 2 \mathrm{H}_{2} \mathrm{O}$ by ammonium hydroxide addition was selected since it fully parallels the conditions of synthesis of HAp. For the preparation of the nanocomposites, the zinc precursor was added to $200 \mathrm{~mL}$ of the calcium and phosphate-containing solution originating from ore dissolution and a concentrated solution of $\mathrm{NH}_{4} \mathrm{OH}(25 \%)$ was added up to $\mathrm{pH}=10$ under continuous stirring at room temperature. The amount of added precursor was varied to obtain a theoretical final $\mathrm{ZnO}: \mathrm{HAp}$ weight ratio $w=5$, 10,25 and $40 \%$ and the resulting materials were named wZnHAp. The resulting gelatinous precipitates were aged for $24 \mathrm{~h}$. After dispersion in water under ultrasound irradiation, the precipitates were filtered and washed three times with water with intermediate ultrasound irradiation steps to optimize grain dispersion. Finally, the powders were dried in an oven at 100 ${ }^{\circ} \mathrm{C}$ for $24 \mathrm{~h}$ or $500^{\circ} \mathrm{C}$ for $3 \mathrm{~h}$.

The resulting solids were characterized using X-ray powder diffraction (XRD) (Philips $\mathrm{PW} 131$ diffractometer, $\mathrm{Cu} \mathrm{K} \alpha$ radiation). Nitrogen sorption isotherms were recorded at $77 \mathrm{~K}$ using a Micromeretics ASAP 2010 instrument. Specific surface areas $\left(S_{B E T}\right)$ and porous volume $(V p)$ were calculated according to the Brunauer-Emmet-Teller (BET) method whereas the average pore 
size $(D p)$ were calculated using the BJH model. Chemical analyses were performed by inductively coupled plasma atomic emission spectroscopy (ICP-AES).

\subsection{Adsorption and photodegradation procedures}

The kinetics of the sorption of ciprofloxacin (CIP, 1-Cyclopropyl-6-fluoro-1,4-dihydro-4-oxo-7(1-piperazinyl)-3-quinolinecarboxylic acid) and ofloxacin (OFL, (R,S)-9-Fluoro-2,3-dihydro-3methyl-10-(4-methyl-1-piperazinyl)-7-oxo-7H-pyrido(1,2,3-de)-1,4-benzoxazine-6-carboxylic acid) antibiotics (Fig. 1) on wZnHAp composites were studied using a batch method. Antibiotics aqueous solutions at a $20 \mathrm{mg} \cdot \mathrm{mL}^{-1}$ concentration were prepared in deionized water. $100 \mathrm{~mL}$ of these solutions was placed in a $500 \mathrm{~mL}$ thermostated reactor and $0.2 \mathrm{~g}$ of the thermally-treated samples was added at $25^{\circ} \mathrm{C}$ using a mechanical stirrer (EUROSTAR digital IKA). At different reaction times $(t)$, aliquots of the supernatant solution were taken with a $2 \mathrm{~mL}$ propylene syringe

equipped with a $0.45 \mu \mathrm{m}$ filter and the amount of adsorbed antibiotics $\mathrm{q}_{t}\left(\mathrm{mg} \cdot \mathrm{g}^{-1}\right)$ was measured by the difference between the initial and final concentration of the organic molecule in the solution, as determined by High Performance Liquid Chromatography (HPLC) [26].

These kinetics data were fitted with the linear form of the Lagergren pseudo first-order equation (eq. 1)

$$
\log \left(q_{e, 1}-q_{t}\right)=\log q_{e, 1}-\frac{k_{1}}{2.303} t
$$

where $q_{e, 1}$ is the amount at equilibrium of adsorbed molecule per gram of sorbent (in $\mathrm{mg} \cdot \mathrm{g}^{-1}$ ) and $k_{1}$ is the pseudo-first order rate constant, and the linear form of the Lagergren pseudo-second-order equations (eq. 2) 


$$
\frac{1}{\left(q_{e, 2}-q_{t}\right)}=\frac{1}{q_{e, 2}}+k_{2} t
$$

with $q_{e, 2}$, the amount at equilibrium of adsorbed molecule per gram of sorbent (in $\mathrm{mg} \cdot \mathrm{g}^{-1}$ ) and $k_{2}$ the pseudo-second order rate constant [40]. The Kaleidagraph software used to perform the fitting procedure provided the coefficient of linear determination $\left(R^{2}\right)$.

The photochemical activity of powders heated at $500^{\circ} \mathrm{C}$ was evaluated under a $125 \mathrm{~W}$ UV A-B-C $(200-600 \mathrm{~nm})$ irradiation. A solid sample $(0.2 \mathrm{~g})$ was first dispersed in $100 \mathrm{~mL}$ of antibiotic solution $\left(20 \mathrm{mg} \cdot \mathrm{L}^{-1}\right)$ and left to react in the dark for $30 \mathrm{~min}$. The solution was then exposed to UV light under magnetic stirring. At each selected time, the suspensions were centrifuged at $4000 \mathrm{rpm}$ for $20 \mathrm{~min}$, and the supernatants were stored in the dark before analysis by HPLC.

\section{Results and discussion}

\subsection{Characterization of the nanocomposite powders}

The resulting nanocomposites were characterized by $\mathrm{XRD}$. After drying at $100^{\circ} \mathrm{C}$, broad diffraction peaks of the hydroxyapatite structure were identified for the pure HAp sample at $2 \theta \approx 26^{\circ}$ (002 plane), $31^{\circ}(211), 32^{\circ}$ (112) and $34^{\circ}$ (200) (JCPDS 09-0432) (Fig. 2a). The $\mathrm{ZnO}$ sample showed the main diffraction peaks of the zincite structure at $c a .32^{\circ}(100), 34.5^{\circ}(002)$, $36.5^{\circ}(101), 47.5^{\circ}(102)$ and $57^{\circ}$ (110) (JCPDS 36-1451). Noticeably, these peaks were not evidenced for any of the $w$ ZnHAp powders pattern. In contrast, after heating at $500^{\circ} \mathrm{C}$, the diffraction peaks of the zincite phase were apparent in the 25ZnHAp and 40ZnHAp nanocomposite materials (Fig. 2b). Application of the Scherer formula was difficult in the nanocomposite structures but indicated an average $\mathrm{ZnO}$ crystallite size of $20 \mathrm{~nm}$. Noticeably no secondary phase such as zinc phosphates could be evidenced on the diffractograms. 
ICP-AES analyses were performed to determine the $\mathrm{Ca}, \mathrm{P}$ and $\mathrm{Zn}$ amounts in the nanocomposites. An increase in the final $\mathrm{Zn} / \mathrm{Ca}$ ratio with the amount of introduced of $\mathrm{Zn}$ nitrate was observed (Table 1). However, except for the 40ZnHAp phase, the experimental value was always larger than the expected (theoretical) value. This would suggest that part of the calcium ions have not reacted to form the hydroxyapatite phase. Since no other phases than HAp et $\mathrm{ZnO}$ were evidenced by XRD, the most likely explanation is that a fraction of the $\mathrm{Zn}^{2+}$ ions have substituted $\mathrm{Ca}^{2+}$ in the apatite structure with unreacted calcium ions have remaining in solution and withdrawn during washing step. In favor of this hypothesis is the observation that the $\mathrm{Ca} / \mathrm{P}$ ratio decreases with the increasing $\mathrm{Zn}$ content. This could also contribute to the absence of visible $\mathrm{ZnO}$ diffraction peaks in the $5 \mathrm{ZnHAp}$ sample even after calcination at $500^{\circ} \mathrm{C}$.

The specific surface area of the powders was calculated from $\mathrm{N}_{2}$ sorption measurements (Fig. 3 for dried powders) and application of the BET method. After drying at $100^{\circ} \mathrm{C}$, all $w \mathrm{ZnHAp}$ nanocomposites exhibit close $S_{B E T}$ values in the $250-270 \mathrm{~m}^{2} \cdot \mathrm{g}^{-1}$ range, that are higher than that of pure HAp $\left(165 \mathrm{~m}^{2} \cdot \mathrm{g}^{-1}\right)$ and one order of magnitude larger than for $\mathrm{ZnO}$ alone (Table 1). This strongly suggests that both types of particles are more evenly dispersed (i.e. less aggregated) within the nanocomposite powder. Porous volumes of the different powders follow the same trend with $V p$ in the $0.5-0.6 \mathrm{~cm}^{3} \cdot \mathrm{g}^{-1}$ for nanocomposites compared to $0.3 \mathrm{~cm}^{3} \cdot \mathrm{g}^{-1}$ for HAp and 0.03 for $\mathrm{ZnO}$. Average pore size $D p$ were $11-12 \mathrm{~nm}$ for $w Z \mathrm{nHAp}$, slightly larger $(14 \mathrm{~nm})$ for HAp and significantly smaller $(4 \mathrm{~nm})$ for $\mathrm{ZnO}$. After thermal treatment at $500^{\circ} \mathrm{C}$, all $S_{B E T}$ and $V p$ values significantly decreased. Again, the nanocomposite powders showed larger $S_{B E T}$ and $V p$ values than $\mathrm{HAp}$ and $\mathrm{ZnO}$. Dp values were slightly smaller for all samples except for $\mathrm{ZnO}$ where an increase up to $8 \mathrm{~nm}$ was measured. 
TEM imaging of the dried powders of nanocomposites show aggregates of well-defined hydroxyapatite rod-like particles $c a .30-50 \mathrm{~nm}$ in length, some of them incorporating electron dense nanoparticles 5- $20 \mathrm{~nm}$ in size (Fig. 4). These nanoparticles are clearly more abundant in the 40ZnHAp sample compared to the $25 \mathrm{ZnHAp}$ powder, suggesting that they correspond to a $\mathrm{Zn}$ rich phase. After heating at $500^{\circ} \mathrm{C}$, coalescence of the hydroxyapatite particles is observed, in agreement with the observed decrease in $S_{B E T}$ values, and dense nanoparticles appear to have grown in size. Based on XRD data, these can therefore be attributed to $\mathrm{ZnO}$ nanocrystals. Noticeably, when the pure $\mathrm{ZnO}$ powders were imaged, dense crystals with sizes of $50 \mathrm{~nm}$ or larger are observed, with no clear variation between the dried and heated sample. This suggests that the hydroxyapatite network limits the growth of the $\mathrm{ZnO}$ nanoparticles within the composite powder.

\subsection{Antibiotics adsorption experiments}

Since a higher photocatalytic efficiency was expected for crystalline $\mathrm{ZnO}$ particles, the following studies were performed using $w \mathrm{ZnHAp}$ powders heated at $500^{\circ} \mathrm{C}$. Kinetics of sorption of CIP and OFL were studied at fixed antibiotics and sorbent amount in the dark. The time to reach equilibrium was longer for CIP compared to OFL and it was adsorbed in similar or larger amounts (Fig. 5). For both antibiotics, $\mathrm{ZnO}$ powders showed the lowest sorption at equilibrium. Among HAp-containing powders, the highest sorption was achieved for the lowest $\mathrm{ZnO}$ amount (5ZnHAp) and then this parameter decreased with increasing zinc oxide content. Finally, pure HAp showed comparable or slightly lower sorption at equilibrium than 40ZnHAp.

To analyze these results in more details, two models were evaluated for the fitting of the experimental data. In most cases, the first-order model led to low $\mathrm{R}^{2}$ values whereas values larger than 0.999 could be obtained with the second-order model (Table 2). The values for sorption 
amount at equilibrium varies from $c a .1 .6 \mathrm{mg}^{\cdot} \mathrm{g}^{-1}$ on $\mathrm{ZnO}$ for both antibiotics to $c a .6 .4$ and 5.4 $\mathrm{mg} \cdot \mathrm{g}^{-1}$ on 5ZnHAp for CIP and OFL, respectively. Only a slight difference in sorbed amount was found between the two antibiotics for pure HAp. Kinetics rates were markedly higher for OFL compared to CIP in all situations but especially for Zn-rich phases.

\subsection{Antibiotics photodegradation tests}

In order to achieve the total removal of the studied pharmaceutical compounds, the photochemical activity of wZnHAp powders heated at $500^{\circ} \mathrm{C}$ was evaluated under an UV A-B-C irradiation. A preliminary adsorption period of 30 min was performed in the dark before exposure to UV light. For pure apatite HAp, the adsorption step was quickly followed by a plateau with no clear evidence of photo-induced degradation (Fig. 6). For $\mathrm{ZnO}$, full degradation of CIP was achieved within 20 minutes while it took more than 2 hours to observe the full disappearance of OFL. When nanocomposites are considered, the 5ZnHAp powders were less efficient than $\mathrm{ZnO}$ alone. In contrast, 25ZnHAp and 40 ZnHAp showed a similar CIP degradation capacity and improved OFL degradation capacity (full disappearance after 1 hour) compared to $\mathrm{ZnO}$. This strongly suggests that, within such nanocomposites, the lower fraction of photoactive $\mathrm{ZnO}$ phase is counterbalanced by the higher sorption capacity of the HAp phase, acting as a pre-concentrating surface.

To follow the photodegradation process, the samples were analyzed by HPLC (Fig. 7). For CIP, the peak corresponding to the antibiotic rapidly vanishes with irradiation time with no significant new signal being observed. In contrast, for OFL, the degradation first leads to the presence of a new peak at slightly smaller retention time, whose relative intensity rises with time at the expense of the OFL signal over the first hour. Beyond this irradiation time, both signals 
decrease in intensity whereas other peaks at much shorter retention time become more significant and remain visible after $2 \mathrm{~h}$.

Noticeably, the photodegradation of pharmaceutical tablets containing ciprofloxacin or ofloxacin and several excipients, including titanium dioxide particles, has been studied and showed very similar degradation rates and pathways for both antibiotics [41]. Specifically, a number of degradation products with molecular weights close to that of the starting compounds have been identified, the most abundant resulting from the breakdown of the piperazinyl ring in the 7 or 10 position of the molecular backbone of CIP and OFL, respectively (Fig. 8). In parallel, the efficient full photodegradation of CIP in solution into small organic products using $\gamma-\mathrm{Fe}_{2} \mathrm{O}_{3} @ \mathrm{ZnO}$ composites has been reported in the literature [42]. These data illustrate that diffusion processes are likely to be of paramount importance for the extent of the photodegradation process. This is in agreement with the fact that a second order model was found to be more adapted for fitting the kinetics data, indicating that reaction kinetics depend both on antibiotic and sorbent concentration. In this context, HPLC data suggest that the early degradation products of OFL are easily released in solution and can therefore enter in competition with the pristine antibiotic for further adsorption and degradation (Fig. 8a). In contrast, the degraded forms of CIP may remain adsorbed on the solid phase, being therefore not detectable by HPLC, and undergo further transformation until full degradation (Fig. 8b). The question remains of the observed difference between OFL and CIP. Since these molecules have close molecular weight and main pKa values, such a difference may originate from distinct hydrophobicity, as indicated by their $X \log P 3$ values (http://pubchem.ncbi.nlm.nih.gov) (Fig. 1), with a higher affinity of the most hydrophilic CIP for the hydroxylated inorganic surfaces. Steric effects due to the presence of a six-membered 
heterocycle linked to the pyridine in OFL compared to a three-membered cyclopropyl in CIP can also contribute to this difference.

\section{Conclusion}

We demonstrate that zinc oxide-hydroxyapatite nanocomposites prepared by a solvent-free route are efficient catalysts for the photodegradation of ciprofloxacin and ofloxacin antibiotics in aqueous solutions under UV irradiation. High Zn loadings within the composite structure can even lead to superior activity compared to the oxide phase alone, thanks to the smaller size and better dispersion of the $\mathrm{ZnO}$ nanocrystals. However the two molecules undergo distinct degradation pathways that appear related to their affinity for the photocatalyst surface. Extension to other antibiotics belonging to the same fluoroquinolone family should allow to clarify the underlying mechanisms before exploring a wider range of pharmaceuticals. In parallel, due to the simplicity and versatility of the synthetic process, it is now possible to envision the simultaneous incorporation of several photoactive phases, such as $\mathrm{TiO}_{2}$ or $\mathrm{CeO}_{2}$, to improve further the photocatalytic efficiency of these materials.

\section{Acknowledgments}

The authors thank the CNRS (France) and CNRST (Morocco) for funding this research through the APATENV project of the PICS program 


\section{References}

[1] T. Heberer, K. Reddersen, A. Mechlinski, From municipal sewage to drinking water: fate and removal of pharmaceutical residues in the aquatic environment in urban areas, Water Sci. Technol. 46 (2002) 81-88.

[2] J. Martin, D. Camacho-Muñoz, J.L. Santos, I. Aparicio, E. Alonso, Occurrence of pharmaceutical compounds in wastewater and sludge from wastewater treatment plants: removal and ecotoxicological impact of wastewater discharges and sludge disposal, J. Hazard. Mater. 15 (2012) 40-47.

[3] A. J. Watkinson, E. J. Murby, S. D. Constanzo, Removal of antibiotics in conventional and advanced wastewater treatment: implications for environmental discharge and wastewater recycling, Water Res. 41 (2007) 4164-4176.

[4] A. Jelic, M. Gros, A. Ginebreda, R. Cespedes-Sánchez, F. Ventura, M. Petrovic, D. Barcelo, Occurrence, partition and removal of pharmaceuticals in sewage water and sludge during wastewater treatment, Water Res. 45 (2011) 1165-1176.

${ }^{[5]}$ T. X. Bui, H. Choi, Adsorptive removal of selected pharmaceuticals by mesoporous silica SBA15, J. Hazard. Mater. 168 (2009) 602-608

[6] S. W. Nam, D. J. Choi, S. K. Kim, N. Her, K. D. Zoh, Adsorption characteristics of selected hydrophilic and hydrophobic micropollutants in water using activated carbon, J. Hazard. Mater. 270 (2014) 144-152.

[7] M. M. Huber, S. Canonica, G. Y. Park, U. von Gunten, Oxidation of pharmaceuticals during ozonation and advanced oxidation processes. Environ. Sci. Technol. 37 (2003) 1016-1024. 
[8] G. Boczkaj, A. Fernandes, Wastewater treatment by means of advanced oxidation processes at basic pH conditions: A review, Chem. Eng. J. 320 (2017) 608-633

[9] P. A. Reddy, P. V. Reddy, E. Kwon, K. H. Kim, T. Akter, S. Kalagara, Recent advances in photocatalytic treatment of pollutants in aqueous media, Environ. Int. 91(2016) 94-103.

[10] J. Zhao, C. Chen, W. Ma, Photocatalytic degradation of organic pollutants under visible light irradiation, Top. Catal. 35 (2005) 269-278.

[11] U. I. Gaya, A. H. Abdullah, Heterogeneous photocatalytic degradation of organic contaminants over titanium dioxide: A review of fundamentals, progress and problem, J. Photochem. Photobiol. C 9 (2008) 1-12

[12] K. M. Lee, C. W. Lai, K. S. Ngai, J. C. Juan, Recent developments of zinc oxide based photocatalyst in water treatment technology: A review, Water. Res. 88 (2016) 428-448.

[13] N. L. Fincur, J. B. Krstic, F. S. Sibul, D. V. Sojic, V. N. Despotovic, N. D. Banic, J. R. Agbaba, B. F. Abramovic, Removal of alprazolam from aqueous solutions by heterogeneous photocatalysis: Influencing factors, intermediates, and products, Chem. Eng. J. 307 (2017) 11051115.

[14] F. Fresno, R. Portela, S. Suarez, J. M. Coronado, Photocatalytic materials: recent achievements and near future trends, J. Mater. Chem. A 2 (2014) 2863-2884

[15] J. Mu, C. Shao, Z. Guo, Z. Zhang, M. Zhang, P. Zhang, B. Chen, Y. Liu, High photocatalytic activity of ZnO-carbon nanofiber heteroarchitectures. ACS Appl. Mater. Interfaces 3 (2011) 590596 
[16] V. Eskizeybek, F, Sari, H. Gülce, A. Avci, Preparation of the new polyaniline/ZnO nanocomposite and its photocatalytic activity for degradation of methylene blue and malachite green dyes under UV and natural sun lights irradiations, Appl. Catal. B 119-120 (2012) 197-206

[17] A. Rajeswari, S. Vismaiya, A. Pius, Preparation, characterization of nano ZnO-blended cellulose acetate-polyurethane membrane for photocatalytic degradation of dyes from water, Chem. Eng. J. 313 (2017) 928-937

[18] T. S. Anirudhan, J. R. Deepa, Nano-zinc oxide incorporated graphene oxide/nanocellulose composite for the adsorption and photocatalytic degradation of ciprofloxacin hydrochloride from aqueous solutions, J. Colloid Interface Sci. 490 (2017) 343-356.

[19] K. S. Ranjith, P. Manivel, R. T. Rajendrakumar, T. Uyar, Multifunctional ZnO nanorodreduced graphene oxide hybrids nanocomposites for effective water remediation: Effective sunlight driven degradation of organic dyes and rapid heavy metal adsorption, Chem. Eng. J. 325 (2017) 588-600

[20] J. Fenoll, I. Garrido, M. Pastor-Belda, N. Campilo, P. Viñas, M. J. Yañez, N. Vela, S. Navarro. Solar detoxification of water polluted with fungicide residues using $\mathrm{ZnO}$-coated magnetic particles. Chem. Engin. J. 330 (2017) 71-81.

[21] A. Nzihou, P. Sharrock, Role of phosphate in the remediation and reuse of heavy metal polluted wastes and sites, Waste Biomass Valor. 1 (2010) 163-174

[22] X. Cao, L.Q. Ma, D.R. Rhue, C.S. Appel, Mechanisms of lead, copper, and zinc retention by phosphate rock, Environ. Pollut. 131 (2004) 435-444. 
[23] A. Dybowska, D.A.C. Manning, M.J. Collins, T. Wess, S. Woodgate, E. Valsami- Jones, An evaluation of the reactivity of synthetic and natural apatites in the presence of aqueous metals, Sci. Total Environ. 407 (2009) 2953-2965

[24] H. Bouyarmane, S. El Asri, A. Rami, C. Roux, M.A. Mahly, A. Saoiabi, T. Coradin, A. Laghzizil, Pyridine and phenol removal using natural and synthetic apatites as low-cost sorbents: influence of porosity and surface interactions, J. Hazard. Mater. 181 (2009) 736-741.

[25] K. Lin, Y. Pan, R. Chen, X. Cheng, X. Xu, Study of the adsorption of phenol from aqueous solution onto apatite nanopowders, J. Hazard. Mater. 161 (2009)231-240.

[26] H. Bouyarmane, I. El Hanbali, M. El Karbane, A. Rami, A. Saoiabi, S. Saoiabi, S. Masse, T. Coradin, A. Laghzizil, Parameters influencing ciprofloxacin, ofloxacin, amoxicillin and sulfamethoxazole retention by natural and converted calcium phosphates, J. Hazard. Mater. 291 (2015) 38-44.

[27] K. Achelhi, S. Masse, G. Laurent, C. Roux, A. Laghzizil, A. Saoiabi, T. Coradin, Ultrasoundassisted synthesis of mesoporous zirconia-hydroxyapatite nanocomposites and their dual surface affinity for $\mathrm{Cr}^{3+} / \mathrm{Cr}_{2} \mathrm{O}_{7}^{2-}$ ions, Langmuir 27 (2011) 15176-15184.

[28] H. Yang, S. Masse, M. Rouelle, E. Aubry, Y. Li, C. Roux, Y. Journaux, L. Li, T. Coradin, Magnetically recoverable iron oxide-hydroxyapatite nanocomposites for lead removal, Int. J. Environ. Sci. Technol. 12 (2015) 1173-1182.

[29] H. Bouyarmane, S. Saoiabi, I. El Hanbali, M. El Karbane, A. Rami, S. Masse, A. Laghzizil, T. Coradin, Porous hydroxyapatite- $\mathrm{TiO}_{2}$ nanocomposites from natural phosphates and their decolorization properties, Eur. Phys. J. Special Topics 224 (2015) 1863-1871. 
[30] A. Nakajima, K. Takakuwa, Y. Kameshima, M. Hagiwara, S. Sato, Y. Yamamoto, N. Yoshida, T. Watanabe, K. Okada, Preparation and properties of titania-apatite hybrid films, J. Photochem. Photobiol. A 177 (2006) 94-99.

[31] G. Sheng, L. Qiao, Y. Mou, Preparation of $\mathrm{TiO}_{2} /$ hydroxyapatite composite and its photocatalytic degradation of methyl orange, J. Environ Eng. 137 (2011) 611-616.

[32] K. Kandori, Y. Yamaguchi, M. Wakamura, Photodecomposition of surfactants using Ti(IV)doped calcium hydroxyapatite particles, Colloid Polym. Sci. 295 (2017) 1079-1087.

[33] C. Piccirillo, P. M. L. Castro, Calcium hydroxyapatite-based photocatalysts for environment remediation: characteristics, performances and future perspectives, J. Environ. Manage. 193 (2017) 79-91.

[34] A.Hassani, A. Khataee, S. Karaca, Photocatalytic degradation of ciprofloxacin by synthesized $\mathrm{TiO}_{2}$ nanoparticles on montmorillonite: Effect of operation parameters and artificial neural network modeling, J. Mol. Catal. A: Chem. 409 (2015) 149-161

[35] M. Bobu' A.Yediler, I.Siminiceanu, S.Schulte-Hostede Degradation studies of ciprofloxacin on a pillared iron catalyst, Appl. Catal. B: Environ.83 (2008) 15-23

[36] P. Huo, Y. Tang, M. Zhou, J. Li, Z. Ye, C. Ma, L.Yu, Y. Yan, Fabrication of ZnWO $\mathrm{Zn}_{4} \mathrm{CdS}$ heterostructure photocatalysts for visible light induced degradation of ciprofloxacin antibiotics, J. Ind. Eng. Chem. 37 (2016) 340-346

[37] S. Sood, S. K. Mehta, A.S.K. Sinha, S.K. Kansal, $\mathrm{Bi}_{2} \mathrm{O}_{3} / \mathrm{TiO}_{2}$ heterostructures: Synthesis, characterization and their application in solar light mediated photocatalyzed degradation of an antibiotic, ofloxacin, Chem. Engin. J. 290 (2016) 45-52. 
[38] S. El Asri, A. Laghzizil, A. Saoiabi, A. Alaoui, K. Al Abassi, R. M'hamdi, T. Coradin, A novel process for the fabrication of nanoporous apatites from Moroccan phosphate rock, Colloid Surf. A 350 (2009) 73-78.

[39] A. Kolodziejczak-Radzimska, T. Jesionowski, Zinc oxide-from synthesis to application: a review, Materials 7 (2014) 2833-2881.

[40] Y.S. Ho, Review of second-order models for adsorption systems, J. Hazard. Mater. 136 (2006) 681-689.

[41] U. Hubicka, P. Zmudzki, P. Talik, B. Zuromska-Witek, J. Krzek, Photodegradation assessment of ciprofloxacin, moxifloxacin, norfloxacin and ofloxacin in the presence of excipients from tablets by UPLC-MS/MS and DSC, Chem. Cent. J. 7 (2013) 133

[42] N. Li, J. Zhang, Y. Tian, J. Zhao, J. Zhang, W. Zuo, Precisely controlled fabrication of magnetic 3D $\gamma-\mathrm{Fe}_{2} \mathrm{O}_{3} @ \mathrm{ZnO}$ core-shell photocatalyst with enhanced activity: Ciprofloxacin degradation and mechanism insight, Chem. Eng. J. 308 (2017) 377-385. 
Table 1. Calculated $\mathrm{Ca} / \mathrm{P}$ and $\mathrm{Zn} / \mathrm{Ca}$ ratio from $\mathrm{ICP}$ measurements, theoretical $\mathrm{Zn} / \mathrm{Ca}$ ratio, specific surface area $\left(S_{B E T}\right)$, porous volume $\left(V_{p}\right)$ and average pore size $\left(D_{p}\right)$ from $N_{2}$ sorption for powders treated at $100^{\circ} \mathrm{C}$ and $500^{\circ} \mathrm{C}$

\begin{tabular}{lccccccccc}
\hline & $\mathrm{Ca} / \mathrm{P}$ & $\mathrm{Zn} / \mathrm{Ca} \mathrm{Zn} / \mathrm{Ca}$ & $\mathrm{S}_{\mathrm{BET}} 100 \mathrm{~V}_{\mathrm{p}} 100$ & $\mathrm{D}_{\mathrm{p}} 100$ & $\mathrm{~S}_{\mathrm{BET}} 500$ & $\mathrm{~V}_{\mathrm{p}} 500$ & $\mathrm{D}_{\mathrm{p}} 500$ \\
& & Exp. & The. & $\left(\mathrm{m}^{2} \mathrm{~g}^{-1}\right)$ & $\left(\mathrm{cm}^{3} \mathrm{~g}^{-1}\right)$ & $(\mathrm{nm})$ & $\left(\mathrm{m}^{2} \mathrm{~g}^{-1}\right)$ & $\left(\mathrm{cm}^{3} \mathrm{~g}^{-1}\right)$ & $(\mathrm{nm})$ \\
\hline HAp & 1.89 & - & - & 165 & 0.32 & 14 & 105 & 0.26 & 12 \\
5ZnHAp & 1.78 & 0.12 & 0.06 & 270 & 0.62 & 12 & 165 & 0.35 & 11 \\
10ZnHAp & 1.73 & 0.18 & 0.12 & 265 & 0.58 & 12 & 165 & 0.34 & 11 \\
25ZnHAp & 1.70 & 0.36 & 0.30 & 260 & 0.60 & 12 & 155 & 0.33 & 12 \\
40ZnHAp & 1.65 & 0.48 & 0.48 & 250 & 0.50 & 11 & 135 & 0.22 & 11 \\
ZnO & - & - & - & 20 & 0.03 & 4 & 10 & 0.02 & 9 \\
\hline
\end{tabular}


Table 2. Kinetic rate constants $\left(\mathrm{k}_{\mathrm{i}}\right)$ and adsorption capacities $\left(\mathrm{q}_{\mathrm{e}, \mathrm{i}}\right)$ as obtained by using pseudofirst order and pseudo-second order models for CIP and OFL sorption on heated wZnHAp composites and pure HAp and $\mathrm{ZnO} . \mathrm{R}^{2}$ indicate the correlation coefficients for the linear fits.

\begin{tabular}{|c|c|c|c|c|c|c|c|}
\hline & & \multicolumn{3}{|c|}{ Pseudo first order } & \multicolumn{3}{|c|}{ Pseudo second order } \\
\hline & & $\mathrm{k}_{1}$ & $\mathrm{q}_{\mathrm{e}, 1}$ & $\mathrm{R}^{2}$ & $\mathrm{k}_{2}$ & $\mathrm{q}_{\mathrm{e}, 2}$ & $\mathrm{R}^{2}$ \\
\hline & & $\left(\min ^{-1}\right)$ & $\left(\mathrm{mg} \mathrm{g}^{-1}\right)$ & & $\left(\mathrm{g} \mathrm{mg}^{-1} \min ^{-1}\right)$ & $\left(\mathrm{mg} \mathrm{g}^{-1}\right)$ & \\
\hline \multirow[t]{2}{*}{ HAp } & CIP & 0.099 & 2.89 & 0.9495 & 0.064 & 4.27 & 0.9999 \\
\hline & OFL & 0.032 & 2.08 & 0.8214 & 0.156 & 4.13 & 0.9999 \\
\hline \multirow[t]{2}{*}{ 5ZnHAp } & CIP & 0.047 & 3.62 & 0.9790 & 0.032 & 6.36 & 0.9998 \\
\hline & OFL & 0.062 & 5.12 & 0.8747 & 0.840 & 5.39 & 0.9999 \\
\hline \multirow[t]{2}{*}{ 10ZnHAp } & CIP & 0.056 & 3.23 & 0.9627 & 0.038 & 5.47 & 0.9995 \\
\hline & OFL & 0.050 & 2.51 & 0.9693 & 0.844 & 4.78 & 0.9998 \\
\hline \multirow[t]{2}{*}{ 25ZnHAp } & CIP & 0.140 & 4.22 & 0.9844 & 0.063 & 4.83 & 0.9993 \\
\hline & OFL & 0.059 & 2.95 & 0.8093 & 1.271 & 4.56 & 0.9993 \\
\hline \multirow[t]{2}{*}{ 40ZnHAp } & CIP & 0.073 & 2.21 & 0.9224 & 0.081 & 4.65 & 0.9998 \\
\hline & OFL & 0.023 & 1.65 & 0.9159 & 1.256 & 4.13 & 0.9997 \\
\hline \multirow[t]{2}{*}{$\mathrm{ZnO}$} & CIP & 0.046 & 1.52 & 0.9933 & 0.052 & 1.59 & 0.9940 \\
\hline & OFL & 0.034 & 1.47 & 0.9810 & 1.794 & 1.61 & 0.9951 \\
\hline
\end{tabular}




\section{Figure Captions}

Figure 1. Chemical structure and selected physico-chemical parameters for ciprofloxacin and ofloxacin

Figure 2. X-Ray diffractograms of the $w \mathrm{ZnHAp}$ composite powders compared to pure HAp and $\mathrm{ZnO}$ (a) dried at $100^{\circ} \mathrm{C}$ and (b) calcined at $500^{\circ} \mathrm{C} . \mathrm{Z}=$ zincite; $\mathrm{H}=$ Hydroxyapatite

Figure 3. $\mathrm{N}_{2}$ sorption curves of the $w \mathrm{ZnHAp}$ composite powders compared to pure HAp and $\mathrm{ZnO}$ dried at $100^{\circ} \mathrm{C}$

Figure 4. TEM images of 25ZnHAp (a,d), $40 \mathrm{ZnHAp}(\mathrm{b}, \mathrm{e})$ and $\mathrm{ZnO}(\mathrm{c}, \mathrm{f})$ dried at $100^{\circ} \mathrm{C}(\mathrm{a}-\mathrm{c})$ or heated at $500^{\circ} \mathrm{C}(\mathrm{d}-\mathrm{e})$. White arrows indicate darker nanoparticles attributed to $\mathrm{ZnO}$.

Figure 5. Kinetics of (a) ciprofloxacin and (b) ofloxacin removal $\left(q_{e}\right)$ by the wZnHAp composite powders heated at $500^{\circ} \mathrm{C}$ compared to pure HAp and $\mathrm{ZnO}$. Plain lines show the results of data fitting using the pseudo-second order Lagergren model.

Figure 6. Kinetics of (a) ciprofloxacin and (b) ofloxacin removal $\left(q_{e}\right)$ by the wZnHAp composite powders heated at $500^{\circ} \mathrm{C}$ compared to pure $\mathrm{HAp}$ and $\mathrm{ZnO}$ during a first $30 \mathrm{~min}$ period in the dark following by irradiation using a $125 \mathrm{~W}$ UV A-B-C lamp.

Figure 7. HPLC analysis of (a) CIP and (b) OFL solutions during the photodegradation test.

Figure 8. Proposed mechanisms of (a) CIP and (b) OFL photodegradation. Chemical structure of main primary photodegradation products was based on the literature [41]. 
Figure 1.

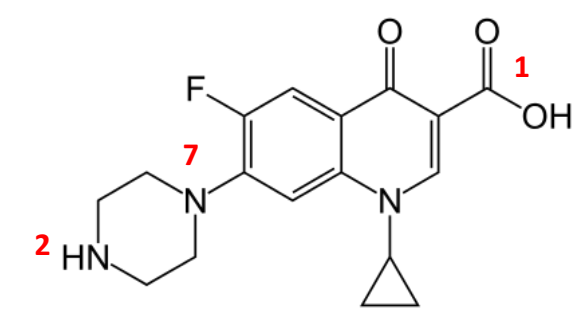

Ciprofloxacin (CIP)

$M W=331.3 \mathrm{~g} \mathrm{~mol}^{-1}$

$p K a_{1}=6.1 ; p K a_{2}=8.7 ; X \log P 3=-1.1$

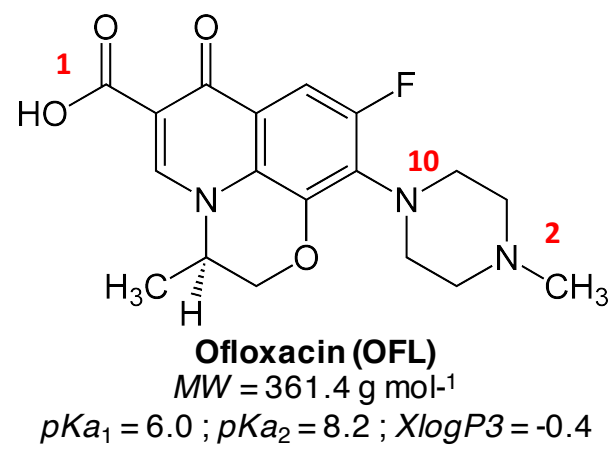

$p K a_{1}=6.0 ; p K a_{2}=8.2 ; X \log P 3=-0.4$ 
Figure 2.

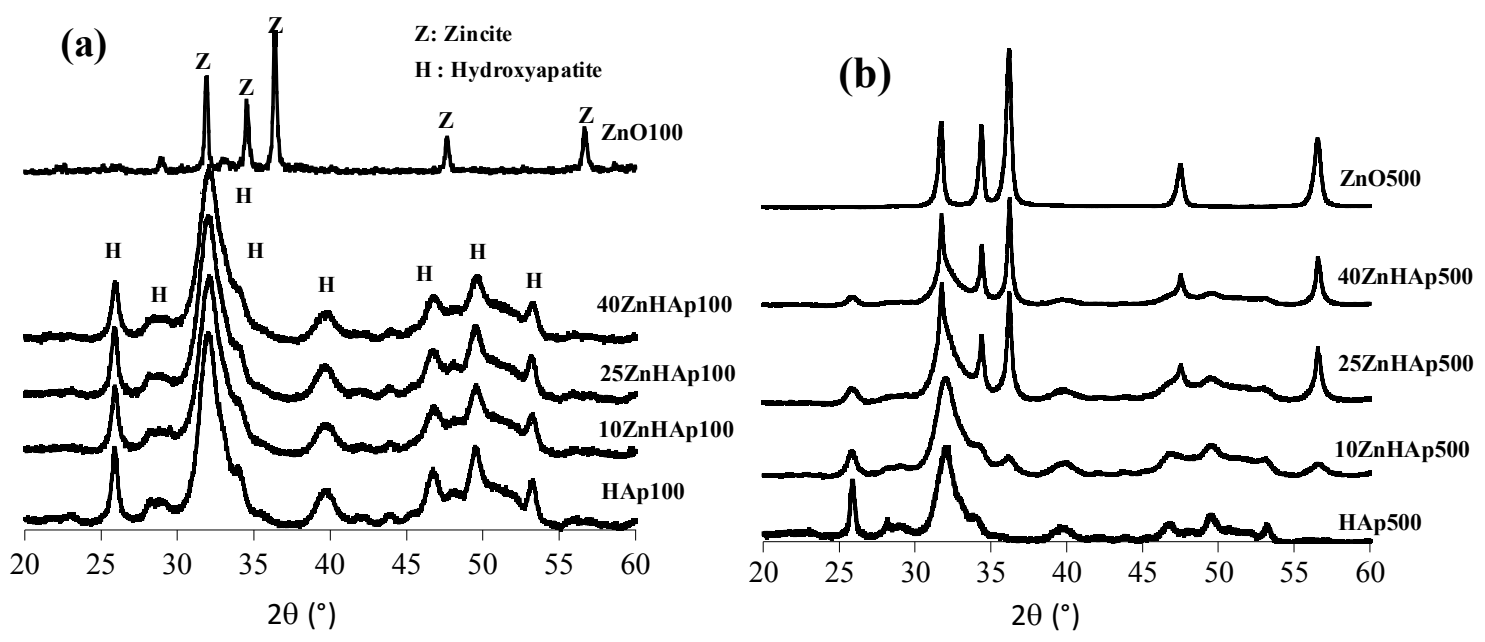


Figure 3.

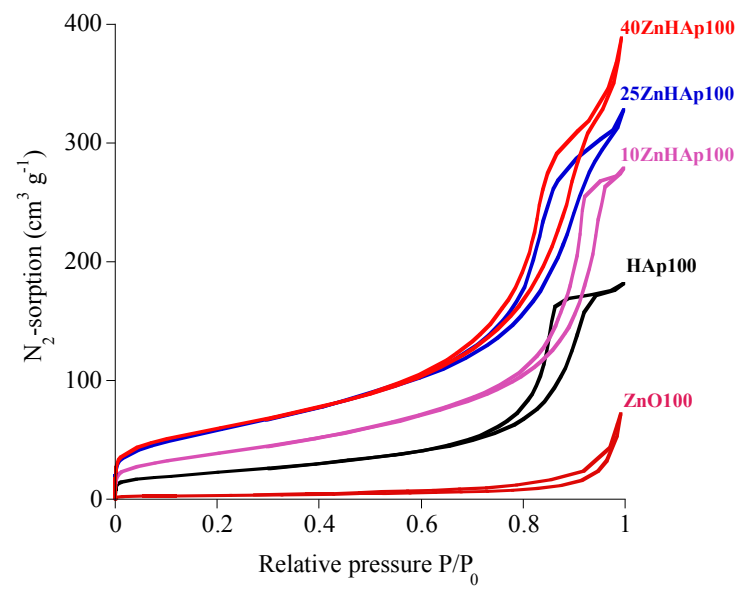


Figure 4.
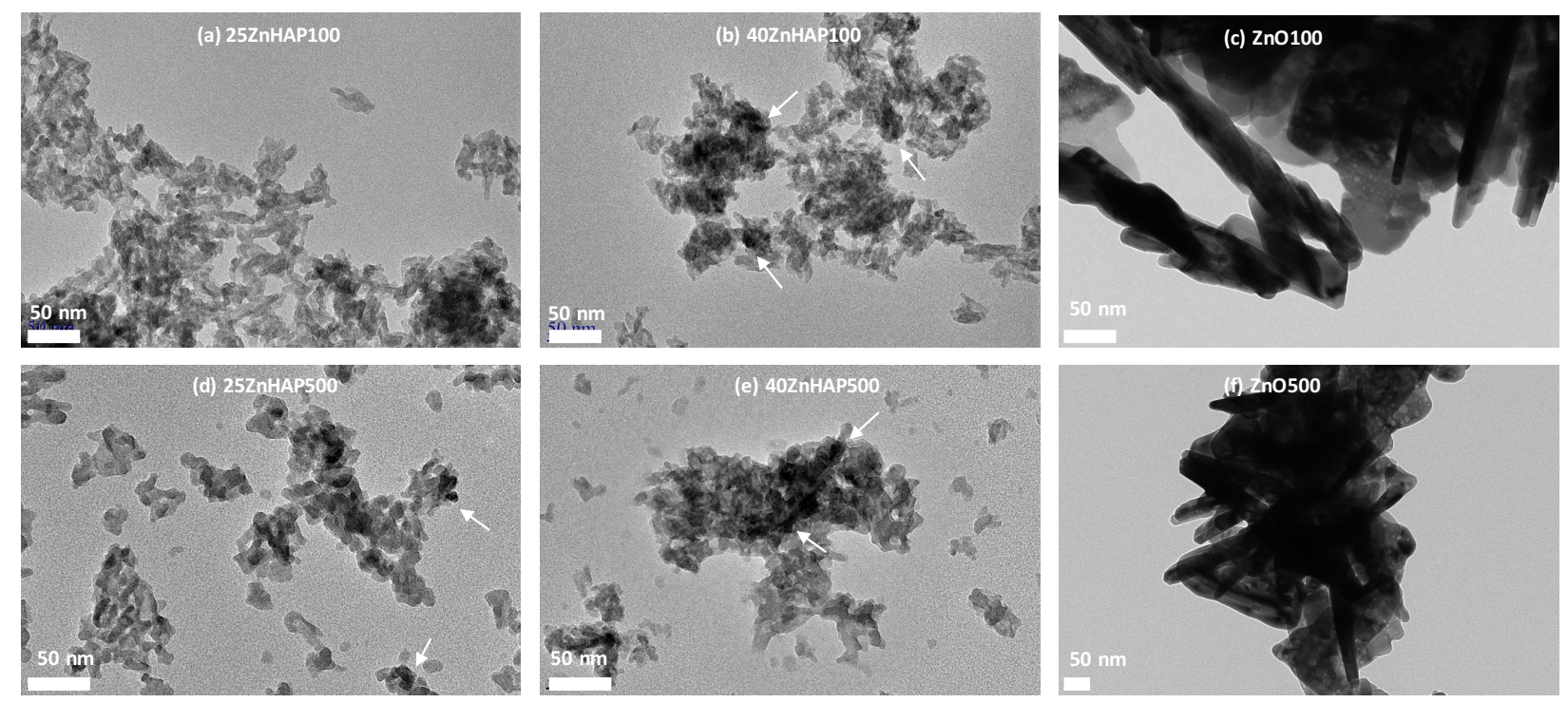
Figure 5.
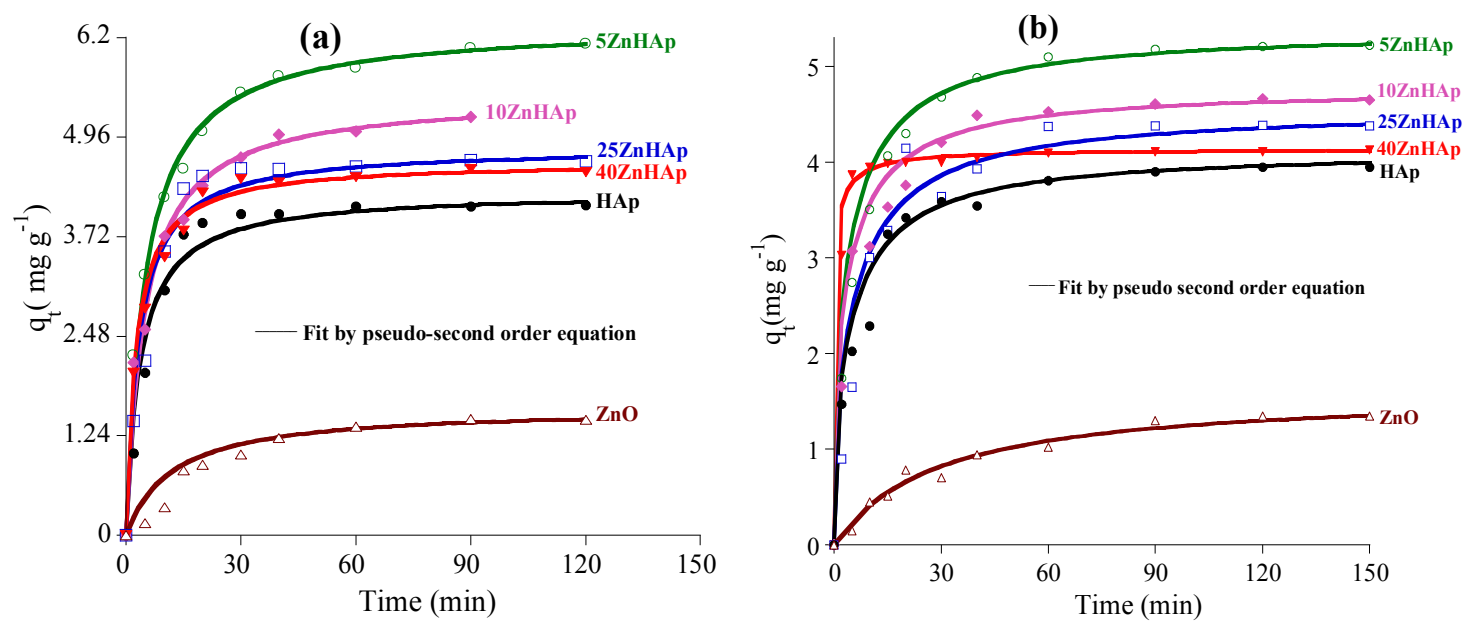
Figure 6.
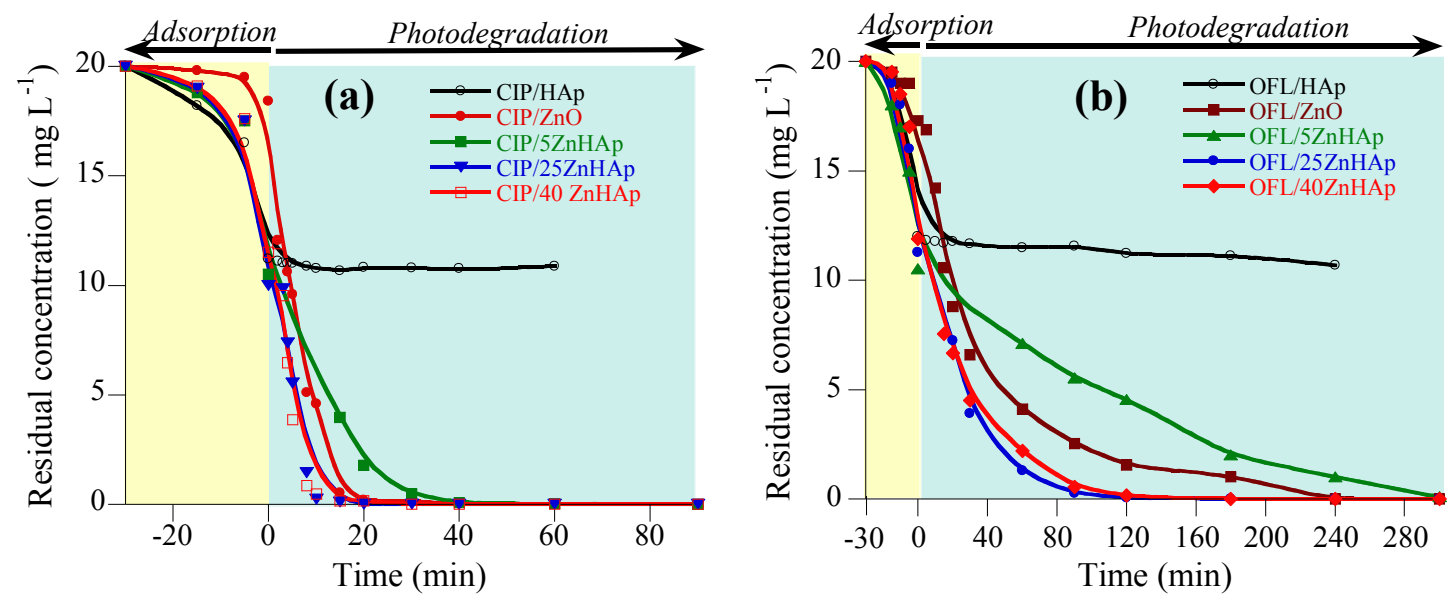
Figure 7.

(a)

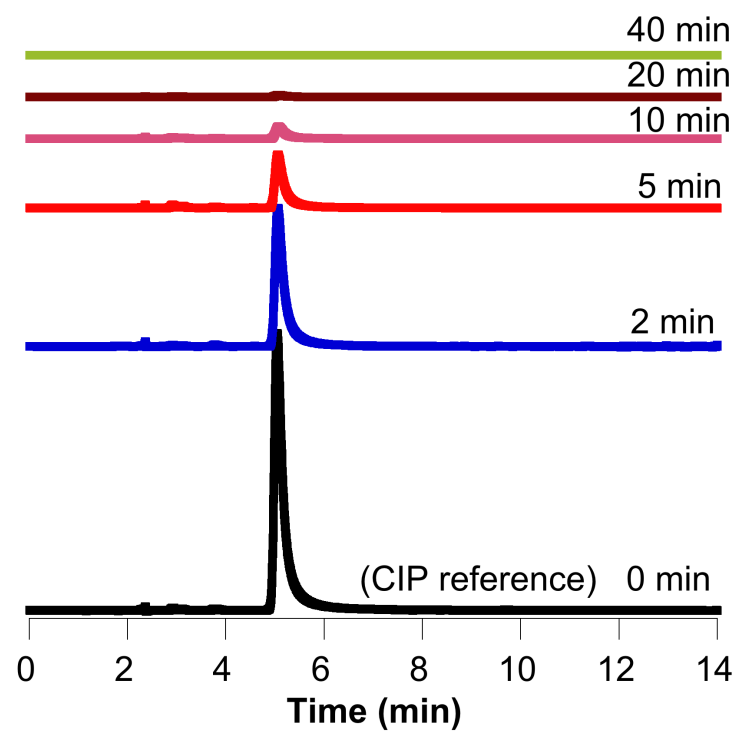

(b)

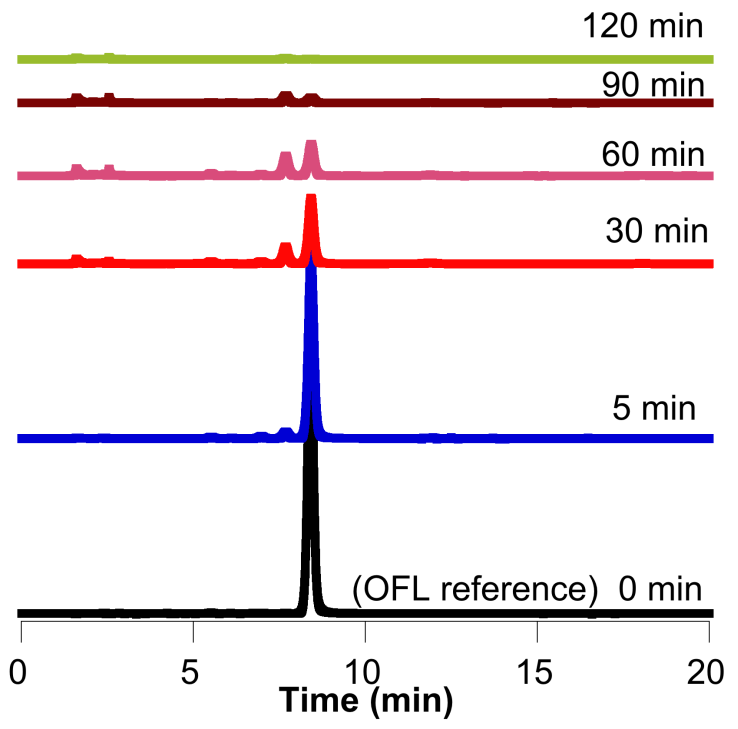


Figure 8.

(a) CIP

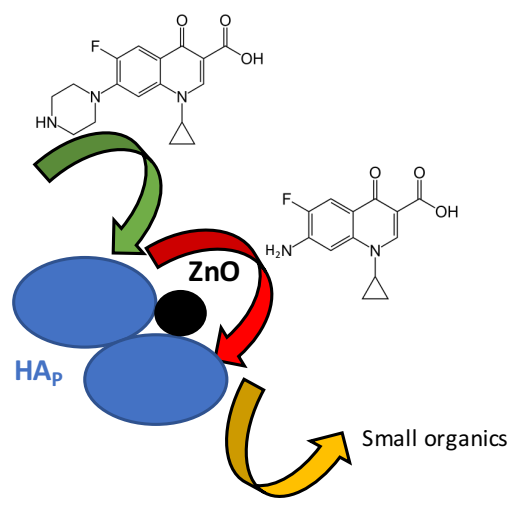

(b) OFL

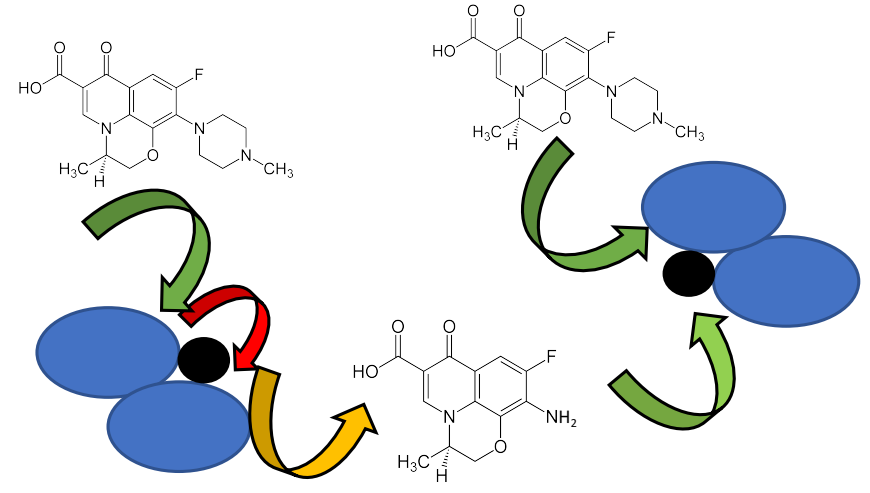

